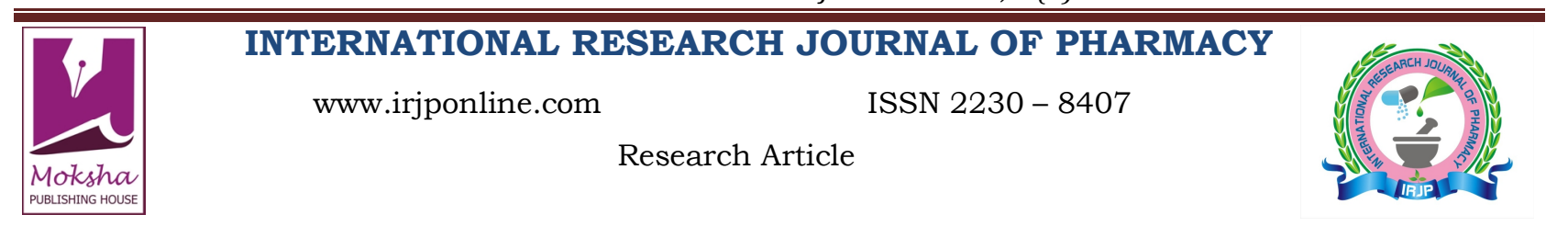

\title{
PREMENSTRUAL SYNDROME SYMPTOMS (PMS) AND PREVALENCE AMONG UNIVERSITY STUDENTS IN KARACHI, PAKISTAN
}

Zehra Sitwat $^{1}$, Azhar Abid ${ }^{1}$, A. Arif ${ }^{1}$, Ansari Basit ${ }^{2}$, Qureshi Masood Anwar ${ }^{3}$

${ }^{1}$ The Karachi Institute of Biotechnology and Genetic Engineering (KIBGE), University of Karachi, Karachi, Pakistan

${ }^{2}$ Department of Health \& Physical Education University of Karachi, Karachi, Pakistan

${ }^{3}$ Department of Physiology, Dow University of Health Sciences, Ojha Campus, Karachi, Pakistan

Email basitansari@hotmail.com

Article Received on: 10/02/13 Revised on: 01/03/13 Approved for publication: 11/04/13

DOI: $10.7897 / 2230-8407.04420$

IRJP is an official publication of Moksha Publishing House. Website: www.mokshaph.com

(C) All rights reserved.

\section{ABSTRACT}

A cross-sectional study was designed to investigate the frequency of PMS, on 520 subjects selected from University of Karachi (mean age 20 \pm 1.94 ). The PMS and menstrual cycle data of individuals were collected from prism calendar and symptom-thermal chart for three consecutive cycles. Based on the observations, all subjects were grouped as control (208) and PMS patients (312). The frequency (60\%) with symptoms include irritability (71.05\%), fatigue $(86.84 \%)$, and bowel constipation $(36.76 \%)$ and loose bowel $(17.65 \%)$, appetite up $(42.65 \%)$, and appetite down $(51.47 \%)$.Breast tenderness $(67.65 \%)$, abdominal blotting (47.06\%), aggressiveness (29.41\%), depression (13.24\%), and insomnia (14.71\%), labile mood (5.88\%), and anger (7.35\%). Elevated irritability and breast tenderness were observed in age group (19-24 years) i.e. $92 \%$ and $82 \%$ respectively with p $<0.001$. The present study identified a pattern non-similar to the typical PMS pattern of the Western populations. The typical socio-cultural habitat of Pakistani population, may have led to the evolution of a different pattern of PMS.

Keywords: Premenstrual syndrome, menstrual cycle, students, breast tenderness, irritability

\section{INTRODUCTION}

Premenstrual syndrome (PMS) has been defined as a combination of distressing and menstrual related dysfunctions involving physical, psychological and or behavioral changes of sufficient severity causing ill-effect on interpersonal relationship or interference with normal activity 28. Its clinical features, screening, diagnosis, epidemiology, etiology, and treatment strategies reviewed recently highlighted its importance in women's reproductive health ${ }^{5}$, $10,13,19,25$. The data on PMS symptomatology has been reported in different populations; however, information about its etiology, with respect to proper diagnosis and treatment is needed $^{33}$. There occurs overlap between PMS and atypical symptoms and variability in methodology produced further problems in understanding this syndrome ${ }^{18,22}$. Different socio-cultural factors in Pakistan as compared to western countries may influence PMS as indicated by a recent study on Chinese women who showed overlapping and distinct features when compared with pattern in west ${ }^{18}$.

\section{MATERIALS AND METHOD}

The retrospective study was conducted at random on 520 adult, healthy female volunteers with average age of $20 \pm 1.94$ years, taken from University of Karachi. An approval from the Ethical Committee of the Institute was taken before the recruitment of the volunteers. Care was taken however, that the subjects do not have any major disease and are not on drugs. They belong to an average socio-economic status, not specifically from any particular community, area or locality. They were handed over the questionnaires, BBT charts, thermometers to records and provide the required information for at least three consecutive menstrual cycles. While issuing the questionnaire, the subjects were asked to submit their personal physical data including, name, residential address, telephone number, height, weight, age of menarche, etc.

\section{RESULT}

The menstrual cycle characteristics including menarche, menstrual cycle length, follicular phase, luteal phase and presumptive day of ovulation did not show any significant differences between PMS and controls (Figure 1). The most frequent reported symptoms includes irritability (71.05\%), fatigue $(86.84 \%$ ), Bowel (cons. and loose as low as $36.76 \%$ and $17.65 \%$ respectively) and appetite (up and down as 42.65 and $51.47 \%$ respectively). Symptoms like breast tenderness, Abdominal blotting, Aggressiveness, Depression, Insomnia, Labile mood, and Anger were 67.65\%, 47.06, 29.41\%, $13.24 \%, 14.71 \%, 5.88 \%$ and $7.35 \%$ respectively (Figure 2 ). Elevated irritability and Breast swelling /tenderness were observed in younger age group from 19-24 years that were $92 \%$ and $82 \%$ respectively with $\mathrm{p}<0.001$ (Table $1 \& 2$ ).

Table 1: Association between Age and Breast Swelling / Tenderness

\begin{tabular}{|c|c|c|c|}
\hline $\begin{array}{c}\text { Socio-demographic } \\
\text { characteristics }\end{array}$ & \multicolumn{2}{|c|}{ Breast Discomfort } & \multirow{2}{*}{ p value } \\
\cline { 2 - 3 } & Yes \% & No \% & \\
\hline 19-24 years & 82 & 18 & 0.001 \\
$25-30$ years & 5 & 95 & \\
\hline
\end{tabular}

Table 2: Association between Age and Irritability

\begin{tabular}{|c|c|c|c|}
\hline \multirow{2}{*}{$\begin{array}{c}\text { Socio-demographic } \\
\text { characteristics }\end{array}$} & \multicolumn{2}{|c|}{ Irritability } & \multirow{2}{*}{ p value } \\
\cline { 2 - 3 } & Yes \% & No \% & \\
\hline 19-24 years & 92 & 8 & 0.001 \\
25-30 years & 11 & 89 & \\
\hline
\end{tabular}




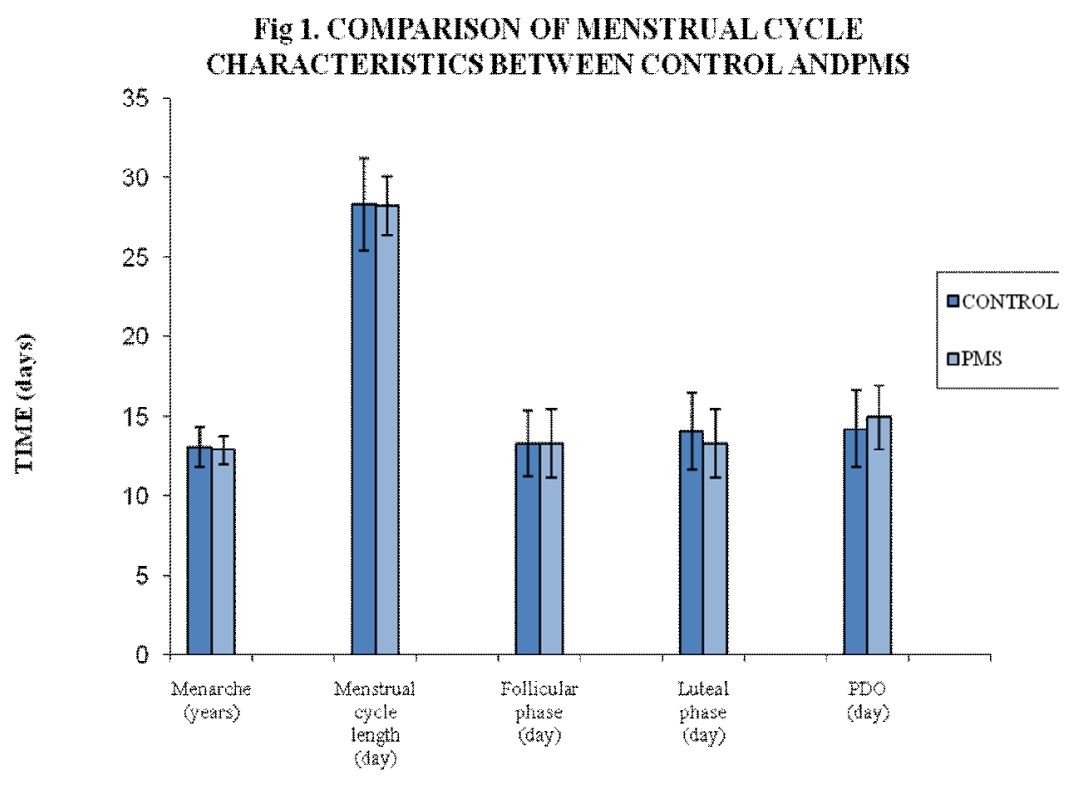

MENSTWAI,CYSTIE CHARACTERISTICS

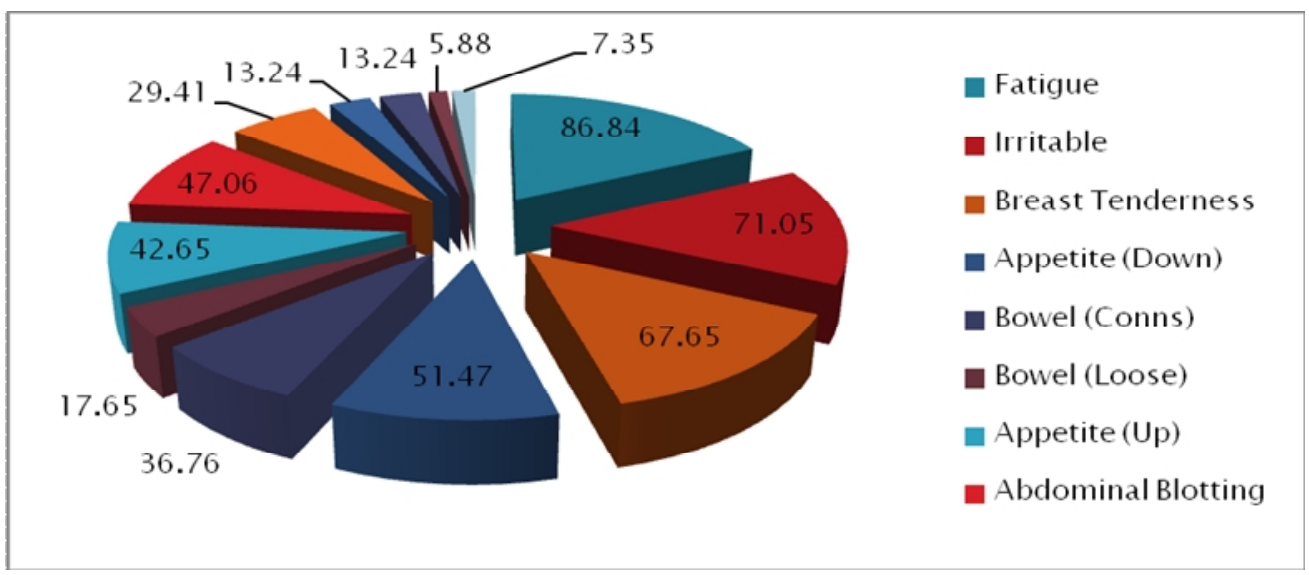

Figure 2: Percentage of symptoms identified during premenstrual phase in PMS subjects

\section{DISCUSSION}

PMS, a disorder of menstrual cycle in adolescent females, though has been defined on different scientific and cultural approaches by both scientists and medical practitioners and but failing to agree on an established one. It may be considered as a medical condition or a scientific issue based on gender based social customs and dealing with behavior and moods hence variety of cultures may give it a different perception ${ }^{9,14,15,26}$.

The present investigation studied the occurrence of premenstrual symptoms using daily symptoms ratings and some of the physiological profiles like BMI, BMR, WHR, $\mathrm{HR}$ and BP in Pakistani adolescent age group (mean age; 21.years). It shows that intense, physical and emotional (i.e. physical behavioral and psychological) changes that disturb the life of affected women, are commonly present in the subjects under study; almost $60 \%$ reported to be associated with the premenstrual phase; The frequency may seem higher as compared to one reported (53\%: $42 \%$ mild, $18.2 \%$ moderate and $31.7 \%$ severe) for young medical undergraduates in Peshawer ${ }^{28}$. The frequency and severity of PMS was studies in city of Hyderabad (Pakistan) Using Short Form 36 (Sf - 36) PMS criteria was met by $51 \%$; of which
$59.5 \%$ had mild, $29.2 \%$ moderate $11.2 \%$ had severe form of $\mathrm{PMS}^{20}$.However, a report from India showed 63.1\% (13-19 years age group) having one or the other symptoms of PMS and a cross-sectional school survey among adolescent females in Malaysia showed majority $(74.6 \%)$ experienced menstrual problems which are influenced by certain modifiable factors ${ }^{18}$. PMS in Indian medical students was found as the second most $(60.50 \%)$ prevalent disorder ${ }^{30}$.

At least one premenstrual symptom was experienced by $96.6 \%$ and $37.5 \%$ had a high symptom severity score in population from Damam ${ }^{27}$ emphasizing bio psychosocial factors. Another study in Saudi Arabia found 36\% prevalent (45\% mild, $32.6 \%$ moderate and $22.4 \%$ severe) using different questionnaires covering ACOG PMS diagnostic criteria supporting the socio-cultural impact on its occurrence ${ }^{4}$. The frequency and severity of the PMS symptoms, in fertile Turkish women (15 and 49 years age group) through various ways of data collection found that $6.1 \%$ had severe PMS symptoms and $72.2 \%$ of these women had some dysfunction as defined by DSM-IV ${ }^{2}$. Using the same criteria another study from Turkey documented the frequency of PMS associated symptoms in 61.4\%: $49.5 \%$ had mild, 39 moderate and 14 severe form ${ }^{7}$.In a study on Iranian 
women (age 18-27 yrs), it was almost 98\%, showing at least one mild to severe PMS symptoms but only $16 \%$ based on DSM-IV criteria ${ }^{3}$. The frequency of PMS associated symptoms in adolescent Turkish girls using modified Diagnostic and Statistical Manual of Mental Disorders-IV (DSM IV) showed 61.4\% met the criteria for PMS (49.5\% had mild, 39 moderate and 14 severe form) ${ }^{7}$.In a later study the frequency PMS among medical students of Turkey was $72 \%$ as determined by using a developed 'Questionnaire Form', PMS Rating Scale" and "Life Quality Scale" 23.

The prevalence of premenstrual symptomatology was $50.1 \%$ in Nigerian female undergraduates (age group, ${ }^{1}$ whereas the prevalence adolescent schoolgirls (12-18 years) in UAE, based on ACOG criteria/structured questionnaire showed that although frequency was low (17. \%) but associated mainly with ethnicity and family history ${ }^{29}$. A study in urban African-American adolescents (age 12-21 years) found to have PMS as the most prevalent reported (84.3\%) disorder (Houston et. al., 2006) whereas PMS among Ethiopian girls was present in $76 \%{ }^{34}$.

Prevalence of premenstrual symptoms and of PMS in women aged 15 to 54 years found $91 \%$ with at least one symptom, $10.3 \%$ had PMS, was higher in non-married women, in women aged 35-44 years and in women of the Italianspeaking region of Switzerland ${ }^{32}$.The study from UK reported premenstrual symptoms in $95 \%$ of women of reproductive age but severe, debilitating symptoms suggestive of PMS occur in about 5\% of those women. This report after searching various databases and relevant organizations (52 reviews) indicates that there is no consensus on assessment/rating scales for severity of symptoms, which obviously affects the treatment approach ${ }^{17}$. Identification of $4.1 \%$ and $8.1 \%$ women as having severe (6 symptoms) to moderate (1-5 symptoms) PMS was reported in French women ${ }^{24}$.

A cross-sectional survey on random telephonic information throughout European, Brazil and Mexico countries with a check of 23 premenstrual symptoms, socio-demographic variables and lifestyle variables found abdominal bloating, cramps or abdominal pain, breast tenderness, irritability and mood swings as the most prevalent symptoms Subjects were categorized according to severity of mental and physical dimensions: 'Mild' type (40.8\%) with minimal symptoms; 'Moderate M' type (28.7\%) with moderately severe, mostly mental symptoms 'Moderate P' type (21.9\%) with moderately severe, mostly physical symptoms; and 'Severe' type (8.6\%) with severe intensity of both mental and physical symptoms. It was recommended that a brief symptom list could be developed as a valid and reliable globally ${ }^{6}$. The symptoms during the present study the most frequent reported symptoms belong to both physical and psychological and behavioral; predominant the later. The most frequent reported symptoms include fatigue $(86.84 \%)$, irritability $(71.05 \%)$, and breast tenderness $67.65 \%$; appetite (up and down as 42.65 and $51.47 \%$ respectively).

Bowel (cons. and loose as low as $36.76 \%$ and $17.65 \%$ respectively); abdominal bloating, 47\%; aggressiveness; 29.5\%; depression; $13 \%$; insomnia; $12 \%$; labile mood, $5.88 \%$ and; anger; $7 \%$. The PRISM Calendar listed 24 symptoms; but for the present study some of these e.g. sex drive (up and down; feel unattractive) were omitted according to Pakistan socio-cultural set-up; Previously, an observational study in Peshawar (Pakistan), the order of frequency of symptoms occurring in PMS was general body discomfort, anxiety, backache, fatigue and depression; most frequently reported symptoms in PMDD group were anger, anxiety, stress, depression, fatigue and general body discomfort ${ }^{31}$.

Most common symptoms reported for an Iranian study reported included were feeling of tiredness or lethargy (84\%), depressed mood $(72.3 \%)$, sudden feeling of sadness or tearfulness $(70.3 \%)$, anxiety $(70 \%)$, backache $(69 \%)$ and sleep problems $(66 \%)$. Significantly higher severity of symptoms was found in the younger women (18-20 years) than in older women (21-24 and 25-27 years) ${ }^{3}$.

A reduced set of symptoms (6 core ones) that best discriminated PMS in prospective daily diary ratings were identified using prospective daily symptoms with optimal cutoff points in the symptom rating/scores for clinical use. Further, the association of these symptoms with functional impairment was determined. The identified core symptoms included: anxiety/tension, mood swings, aches, appetite/food cravings, cramps, and decreased interest in activities. The study classified $84 \%-86 \%$ of PMS cases and recommended the concept that a clinical diagnosis of PMS can be developed around a core symptom group 12 .

Based on 22 PMS behavioral and physical symptoms, as a component of COPE over two consecutive months the findings provided support for predominantly behavioral symptoms and then for physical symptoms. Reliability data extracted 4 categories of symptoms related to mood, somatic/cognitive, appetitive and fluid retention symptoms recommended as are liable instrument for identifying fluctuations in behavioral and physical symptoms ${ }^{8}$.

In Brazilian population, the principal premenstrual symptoms found were: irritability, abdominal discomfort, nervousness, headache, and fatigue and breast pain, associating mainly with higher socioeconomic level (Silva et. al., 2006). Perspectives and attitudes of Brazilian women (18-40 years) towards PMS found nervousness/anxiety (76.4\%); mood swings/crying (55.7\%); pain, swelling, and tenderness of the breasts $(37.3 \%)$; and cramps $(45.4 \%)$ as the major emotional and physical symptoms ${ }^{22}$.

More than 200 symptoms of PMS, some key or characteristics, have been reported ${ }^{5}$.These may be predominantly physical (joint pain, muscle pain, back pain, breast tenderness or pain, abdominal swelling or bloating, headaches, skin disorders, weight gain, swelling of extremities) or predominantly psychological and behavioral (changes in appetite, overeating or specific food cravings, fatigues lethargy or lack of energy, mood swings like sadness, crying increased sensitivity of rejection, irritability, anger, sleep disturbance, restlessness, poor concentration, social withdrawal, not in control, lack of interest in usual activities, loneliness, anxiety, depressed mood, confusion, tension and hopelessness), as reported recently ${ }^{21}$.

Occurrence of specific patterns of affected changes with the menstrual cycle is a well known concept. The present study identified a pattern not following the typical PMS pattern; signs of symptoms even during menstrual phase reflecting that Pakistani population because of typical socio-cultural habitat may have evolved a different type of PMS. Observations partly similar to these findings have been reported among Italian university students; a pattern opposite to typical PMS pattern (low symptoms in premenstrual with a mid-cycle increase- $13 \%$ showing depression and anxiety, in addition to the classic PMS pattern (61\%), and individuals demonstrating no cyclical pattern of symptoms (26\%). It was also found out that the women with a strong PMS pattern showed lower average levels of depression/anxiety than women with no cyclical changes. The findings documented in 
the present study may, as in the previous one, suggest that current conception of menstrual-cycle related psychological changes may be redefined to include the mid-cycle pattern or menstrual pattern ${ }^{16}$.It has been observe that as female getting older the symptoms of PMS became severe and sometime worst ${ }^{11}$. But in our studied group these symptoms were severe in younger females (19-25).

\section{CONCLUSION}

The observations and findings during the present study do indicate that there seems an overall impact of socio-cultural specificity as wells as individual variability with an altered response under body's energy homeostasis may characterize numerous symptoms for PMS. It does, therefore, suggest that primarily psycho-physiological approaches should be taken by physicians practicing and counseling through alteration in behavioral lifestyle under educational and reproductive health programs on community basis.

\section{ACKNOWLEDGEMENT}

The study acknowledges the contribution and support of The Karachi Institute of Biotechnology and Genetic Engineering (KIBGE), University of Karachi for providing technical assistant to carry out the biochemical studies.

\section{REFERENCES}

1. Adewuya AO, Loto OM, Adewumi TA. Pattern and correlates of premenstrual symptomatology amongst Nigerian University students. J Psychosom Obstetric Gynaecol. 2009, 30(2):127-32. http://dx.doi.org/ 10.1080/01674820802545446 PMid:19533493

2. Adigüzel $H$, Taşkin EO, Danaci AE.The symptomatology and prevalence of symptoms of premenstrual syndrome in Manisa, Turkey. 2007 Fall; 18(3):215-22.

3. Bakhshani NM, Mousavi MN, Khodabandeh G. Prevalence and severity of premenstrual symptoms among Iranian female university students. J Pak Med Assoc. 2009, 59(4):205-8. PMid:19402278

4. Balaha MH, Amr MA, Saleh Al Moghannum M, Saab Al Muhaidab N. The phenomenology of premenstrual syndrome in female medical students: a cross sectional study. Pan Afr Med J. 2010, 23; 5:4.

5. Dell DL. Diagnostic challenges in women with premenstrual symptoms. Primary Psychiatry. 2004, 11(12):41-46

6. Dennerstein L, Lehert P, Bäckström TC, Heinemann K. Premenstrual symptoms - severity, duration and typology: an international crosssectional study. Menopause Int. 2009, 15(3):120-6. http://dx.doi.org/ 10.1258/mi.2009.009030 PMid:19723682

7. Derman O, Kanbur NO, Tokur TE, Kutluk T. Premenstrual syndrome and associated symptoms in adolescent girls. Eur J Obstet Gynecol Reprod Biol. 2004 Oct 15; 116(2):201-6. http://dx.doi.org/10.1016/ j.ejogrb.2004.04.021 PMid:15358465

8. Feuerstein M, Shaw WS. Measurement properties of the calendar of premenstrual experience in patients with premenstrual syndrome. J Repord Med. 2002 47(4):279-89. PMid:12012879

9. Figert AE. Premenstrual syndrome as scientific and cultural artifact. Integr Physiol Behav Sci. 2005, 40(2):102-13. http://dx.doi.org/ 10.1007/BF02734245 PMid:17393679

10. Freeman E. Premenstrual syndrome and premenstrual dysphoric disorder: definitions and diagnosis. Psychoneuroendocrinology. 2002, 28(3):25-37

11. Freeman E.W., Schweizer E., and Rickels K. Personality factors in women with premenstrual syndrome. Psychosom Med.1995, 57(5):4539. PMid: 8552736

12. Freeman EW, Halberstadt SM, Rickels K, Legler JM, Lin H, Sammel MD. Core Symptoms That Discriminate Premenstrual Syndrome. J Women's Health (Larchmt). 2010. [Epub ahead of print]

13. Henshaw C.A. PMA: diagnosis, etiology, assessment and management. Advances in Psychiatric treatment.2007, 13,139-146 http://dx.doi.org/ 10.1192/apt.bp. 106.003392

14. Ibralic I, Sinanovic O, Memisevic H. Age at menarche and premenstrual syndrome in adolescent girls with intellectual disability in Bosnia and Herzegovina. Res Dev Disabil. 2010, 31(3):800-3. http://dx.doi.org/ 10.1016/j.ridd.2010.02.004 PMid:20207519

15. Johnson SR. Roy J. and Lucille A. Premenstrual syndrome, premenstrual dysphoric disorder, and beyond: a clinical primer for practitioners. Obstet Gynecol. 2004, 104(4):845-59. http://dx.doi.org/ 10.1097/01.AOG.0000140686.66212.1e PMid:15458909
16. Kiesner J. One woman's low is another woman's high: Paradoxical effects of the menstrual cycle. Psychoneuroendocrinology. 2011, 36(1):68-76.http://dx.doi.org/10.1016/j.psyneuen.2010.06.007 PMid:20650571

17. Kwan I, JL. Premenstrual syndrome Clin Evid (Online). 2007 May 1; 2007. Pii: 0806

18. Lee A M, So-Kum Tang C, Chong C. A culturally sensitive study of premenstrual and menstrual symptoms among Chinese women. J Psychosom Obstet Gynaecol. 2009 Jun; 30(2):105-14. Lee LK, Chen PC, Lee KK, http://dx.doi.org/10.1080/01674820902789241 PMid: 19533490

19. Lentz MJ, Woods N, Heitkemper M, Mitchell E, Henker R, Shaver J. Ovarian steroids and premenstrual symptoms: a comparison of group differences and intra-individual patterns. Res Nurs Health. 2007, 30(3):238-49. http://dx.doi.org/10.1002/nur.20188 PMid:17514719

20. Nisar N, Zehra N, Haider G, Munir AA, Sohoo NA. Frequency, intensity and impact of premenstrual syndrome in medical students. J Coll Physicians Surg Pak. 2008, 18(8):481-4. PMid: 18798584

21. O'Brien PM, Bäckström T, Brown C, Dennerstein L, Endicott J, Epperson CN, Eriksson E, Freeman E, Halbreich U, Ismail KM, Panay N, Pearlstein T, Rapkin A, Reid R, Schmidt P, Steiner M, Stud J, Yonkers K. Towards a consensus on diagnostic criteria, measurement and trial design of the premenstrual disorders: the ISPMD Montreal consensus. Arch Women's Ment Health. 2011, 14(1):13-21. http://dx.doi.org/10.1007/s00737-010-0201-3 PMid:21225438

22. Petta CA, Osis MJ, de Pádua KS, Bahamondes L, Makuch MY. Premenstrual syndrome as reported by Brazilian women. Int J Gynaecol Obstet. 2010, 108(1):40-3. http://dx.doi.org/10.1016/j.ijgo.2009.07.041 PMid: 19892346

23. Pinar G, Colak M, Oksuz E. Premenstrual Syndrome in Turkish college students and its effects on life quality. Sex Report Health. 2011, 2(1):217. http://dx.doi.org/10.1016/j.srhc.2010.10.001 PMid:21147455

24. Potter J, Bouyer J, Trussell J, Moreau C. Premenstrual syndrome prevalence and fluctuation over time: results from a French populationbased survey. J Women's Health (Larchmt). 2009, 18(1):31-9. http://dx.doi.org/10.1089/jwh.2008.0932PMid:19105683 PMCid:3196060

25. Rapkin AJ, Winer SA. Premenstrual syndrome and premenstrual dysphoric disorder: quality of life and burden of illness. Expert Rev Pharmacoecon Outcomes Res. 2009, 9(2):157-70. http://dx.doi.org /10.1586/erp.09.14 PMid:19402804

26. Ray S, Mishra SK, Roy AG, Das BM. Menstrual characteristics: a study of the adolescents of rural and urban West Bengal, India. Ann Hum Biol.2010,37(5):668-81. http://dx.doi.org/10.3109/ 03014460903563442 PMid:20166852

27. Rasheed P, Al-Sowielem LS. Prevalence and predictors of premenstrual syndrome among college-aged women in Saudi Arabia. Ann Saudi Med. 2003 Nov-Dec; 23(6):381-7. PMid:16868373

28. Reid RL and Fretts RC. Premenstrual syndrome In: Kenneth L. Becker, Bd. Principles and Practice of endocrinology and metabolism 3rd edition. Philadelphia. 2001.

29. Rizk DE, Mosallam M, Alyan S, Nagelkerke N. Prevalence and impact of premenstrual syndrome in adolescent schoolgirls in the United Arab Emirates. Act Obstet Gynaecol Scand. 2006, 85(5):589-98. http:// dx.doi.org/10.1080/00016340600556049 PMid:16752239

30. Singh A, Kiran D, Singh H, Nell B, Singh P, Tiwari P. Prevalence and severity of dysmenorrheal: a problem related to menstruation, among first and second year female medical students. Indian J Physiol Pharmacol. 2008, 52(4):389-97. PMid:19585756

31. Tabassum S, Afridi B, Aman Z, Tabassum W, Durrani R. Premenstrual syndrome: frequency and severity in young college girls. J Pak Med Assoc. 2005, 5(12):546-9.

32. Tschudin S, Bertea PC, Zemp E. Prevalence and predictors of premenstrual syndrome and premenstrual dysphoric disorder in a population-based sample. Arch Women's Ment Health. 2010, 13(6):48594. http://dx.doi.org/10.1007/s00737-010-0165-3 PMid:20449618

33. Zaafrane F, Faleh R, Melki W, Sakouhi M, Gaha L. An overview of premenstrual syndrome J Gynaecol Obstet Biol Repord (Paris). 2007, 36(7):642-52.

34. Zegeye DT, Megabiaw B, Mulu A. Age at menarche and the menstrual pattern of secondary school adolescents in northwest Ethiopia. BMC Women's Health. 2009, 5; 9:29.

Cite this article as:

Zehra Sitwat, Azhar Abid, A. Arif, Ansari Basit, Qureshi Masood Anwar. Premenstrual syndrome symptoms (PMS) and prevalence among university students in Karachi, Pakistan. Int. Res. J. Pharm. 2013; 4(4):113-116 